OPEN ACCESS

Edited by:

Alessandro Antonelli,

University of Pisa, Italy

Reviewed by:

Roberto Vita,

Università degli Studi di Messina, Italy

Silvia Martina Ferrari,

University of Pisa, Italy

*Correspondence:

Yan Wu

jlwuyan@126.com

Hong-Duo Chen

hongduochen@hotmail.com

Specialty section: This article was submitted to

Thyroid Endocrinology,

a section of the journal

Frontiers in Endocrinology

Received: 16 September 2018 Accepted: 20 December 2018

Published: 15 January 2019

Citation:

Yuan J, Sun C, Jiang S, Lu Y, Zhang Y, Gao X-H, Wu Y and Chen H-D (2019)

The Prevalence of Thyroid Disorders in

Patients With Vitiligo: A Systematic

Review and Meta-Analysis.

Front. Endocrinol. 9:803.

doi: 10.3389/fendo.2018.00803

\section{The Prevalence of Thyroid Disorders in Patients With Vitiligo: A Systematic Review and Meta-Analysis}

\author{
Jinping Yuan, Chong Sun, Shibin Jiang, Yansong Lu, Yuhui Zhang, Xing-Hua Gao, Yan Wu* \\ and Hong-Duo Chen*
}

Key Lab of Immunodermatology, Ministry of Health, Department of Dermatology, The First Hospital of China Medical University, Shenyang, China

Background: Associations between vitiligo and thyroid disorders have been suggested, However, the prevalence of thyroid disorders in vitiligo vary widely.

Purpose: To conduct a systematic review and meta-analysis assessing the prevalence of thyroid disorders in patients with vitiligo.

Method: The PubMed, Cochrane Library, EMBASE, CNKI (China National Knowledge Infrastructure), Chongqing VIP database, and Wanfang database from inception to August 2, 2018 were systematically searched. The pooled prevalence and its 95\% confidence interval $(\mathrm{Cl})$ were calculated.

Results: A total of 77 eligible studies were identified and included, published from 1968 to 2018. Six thyroid disorders including subclinical hyperthyroidism, overt hyperthyroidism, subclinical hypothyroidism, overt hypothyroidism, Graves disease, and Hashimoto thyroiditis were described. The numbers of relative studies were 54 in overt hypothyroidism, 50 in overt hyperthyroidism, 25 in subclinical hypothyroidism, 19 in Hashimoto thyroiditis, 16 in Graves disease, and 10 in subclinical hyperthyroidism. The highest prevalence was 0.06 (95\% Cl: 0.04-0.07) in subclinical hypothyroidism, and the lowest was 0.01 in subclinical hyperthyroidism (95\% Cl: $0.00-0.01)$ or Graves disease (95\% Cl: 0.01-0.02).

Conclusion: Six thyroid disorders showed various prevalence in vitiligo. The highest prevalence was in subclinical hypothyroidism, and the lowest was in subclinical hyperthyroidism or Graves disease. Screening vitiligo patients for thyroid disorders seem plausible, in an effort to detect potential thyroid diseases or to assess the risk of future onset.

Keywords: vitiligo, thyroid disorders, prevalence, systematic review, meta-analysis

\section{INTRODUCTION}

Vitiligo is characterized by the loss of functional skin and mucosal melanocytes, the estimated prevalence is $0.5-2 \%(1,2)$. Currently, the exact pathogenesis of vitiligo remains obscure. The most accredited hypothesis is the autoimmune theory, being sustained by several epidemiological, clinical, and experimental findings (3-5). These studies indicate that melanocyte defects drive vitiligo pathogenesis by triggering an autoimmune response that leads to melanocyte destruction 
in susceptible individuals. Patients with vitiligo are more likely to suffer from autoimmune conditions than the general population (6). Several studies have suggested vitiligo is associated with a variety of other autoimmune diseases, including thyroid conditions, alopecia areata, type 1 diabetes mellitus, pernicious anemia, and rheumatoid arthritis. Among these, thyroid disorders are common conditions in vitiligo patients, and a recent study showed one of the most frequently observed autoimmune diseases in autoimmune thyroiditis patients was vitiligo $(7,8)$. A genetic co-localization between vitiligo and thyroid autoantibodies has also been proposed (9). The British guidelines suggested to check the thyroid function for adult patients with vitiligo, the Dutch guidelines recommend that when patients with vitiligo have clinical symptoms of thyroid disease, thyroid function should be tested $(10,11)$ Herein, we conducted a systematic review and meta-analysis to explore the prevalence of various kind of thyroid disorders in patients with vitiligo.

\section{METHODS}

\section{Electronic Search}

The PubMed, Cochrane Library, EMBASE, CNKI (China National Knowledge Infrastructure), Chongqing VIP database, and Wanfang database were systematically searched with different combinations of key words to identify studies on thyroid disorders in vitiligo. The studies published in the period from inception to August 2, 2018 were identified. The search keywords were [vitiligo] AND [thyroid] with ["prevalence" OR "incidence" OR "epidemiology"]. A manual search was performed by checking the reference lists of key studies and review articles before they were excluded to identify additional studies.

\section{Inclusion and Exclusion Criteria}

Studies were included if they met the following eligibility criteria: (1) provided sufficient information to estimate the prevalence of thyroid disorders in patients with vitiligo; (2) published in either English or Chinese language; (3) had the exact diagnosis of thyroid disorders. The exclusion criteria were duplicate data, irrelevant to vitiligo, review, data mistake, not providing sufficient information. Obscure terms, such as thyroid disfunction, thyroid disease, and autoimmune thyroid disease, or no categorical diagnoses were excluded.

\section{Data Extraction}

Data was extracted from each article using a standardized dataabstraction form, designed in advance. All the potentially relevant papers were reviewed independently by two investigators. Disagreements were resolved through discussion. The following

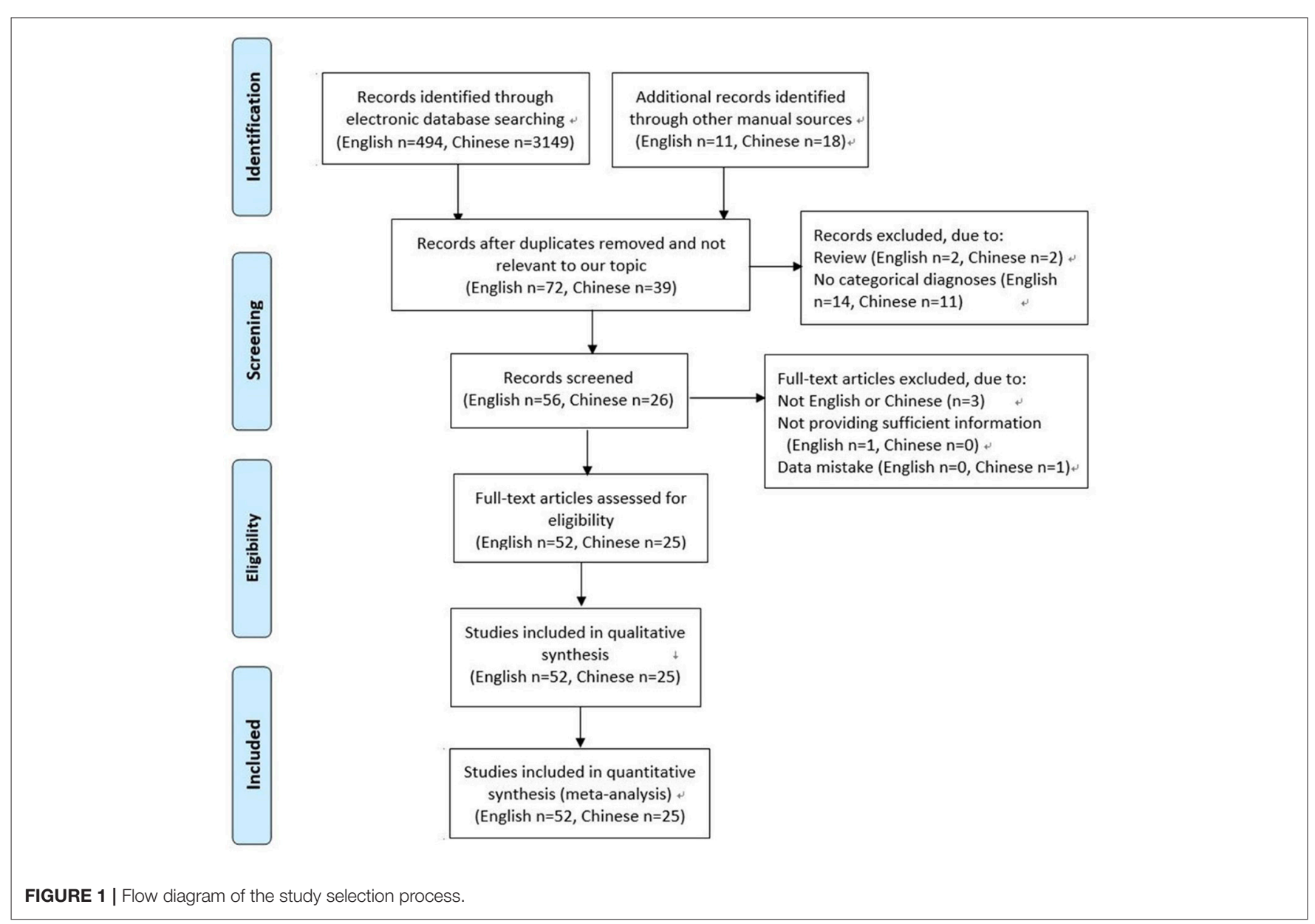




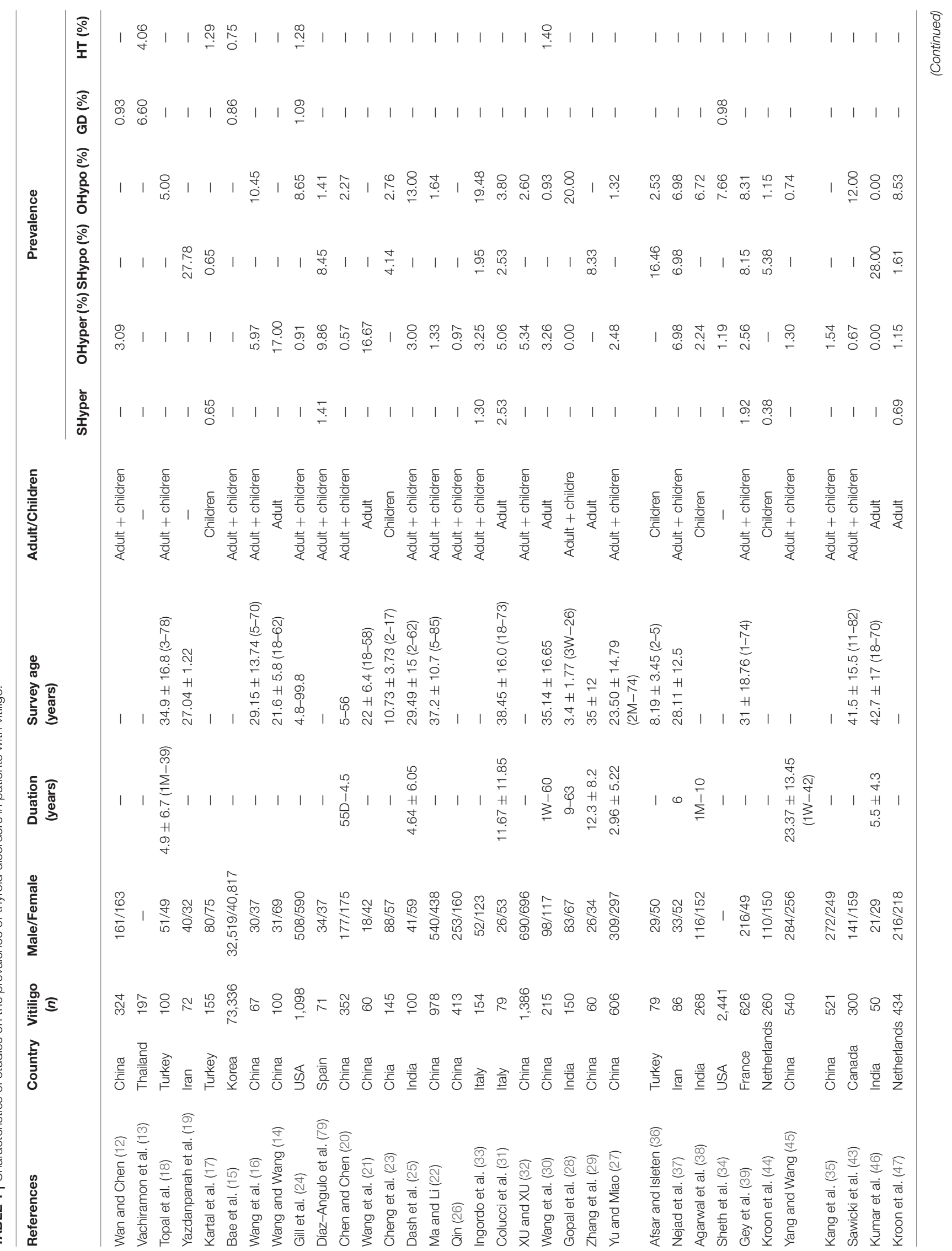




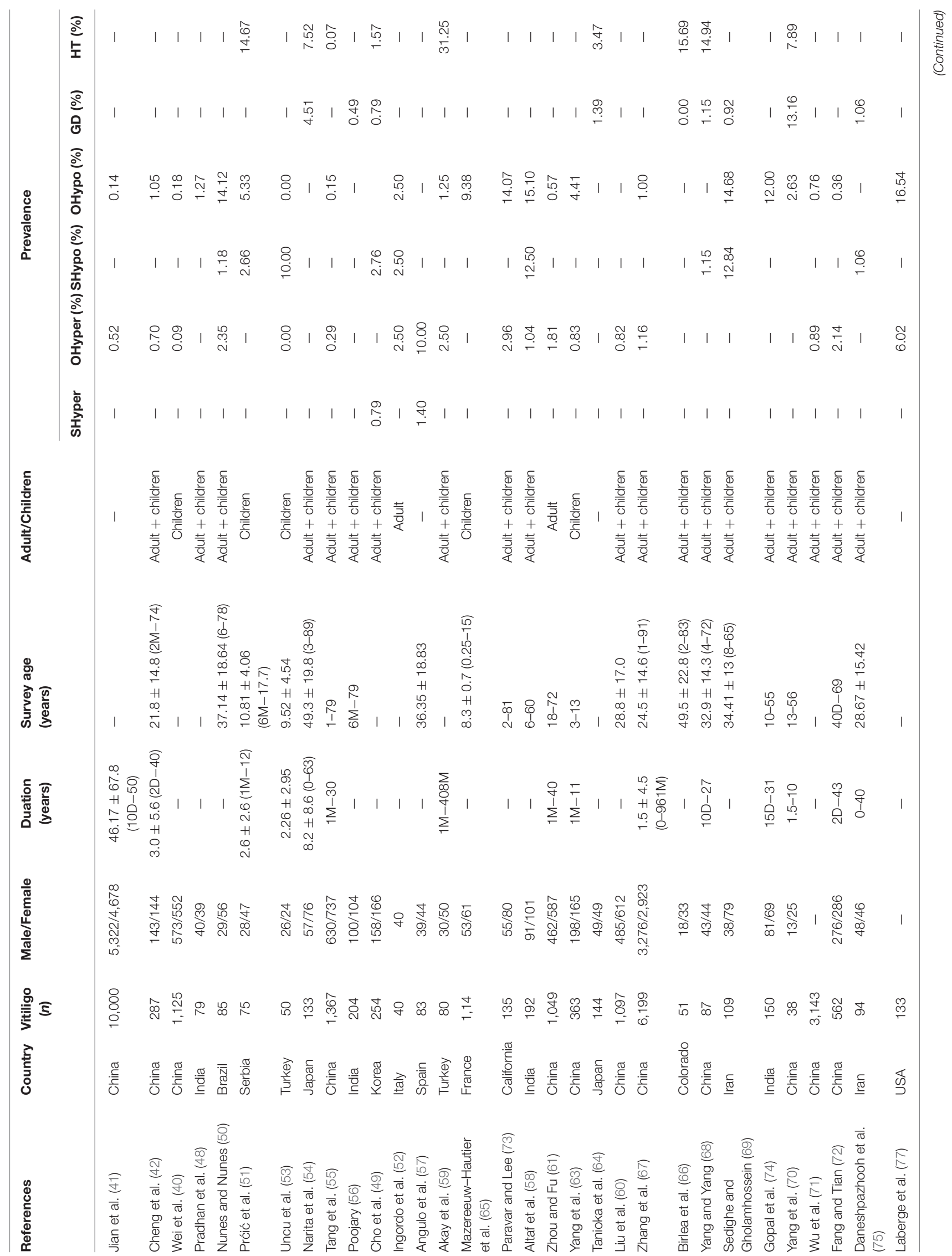




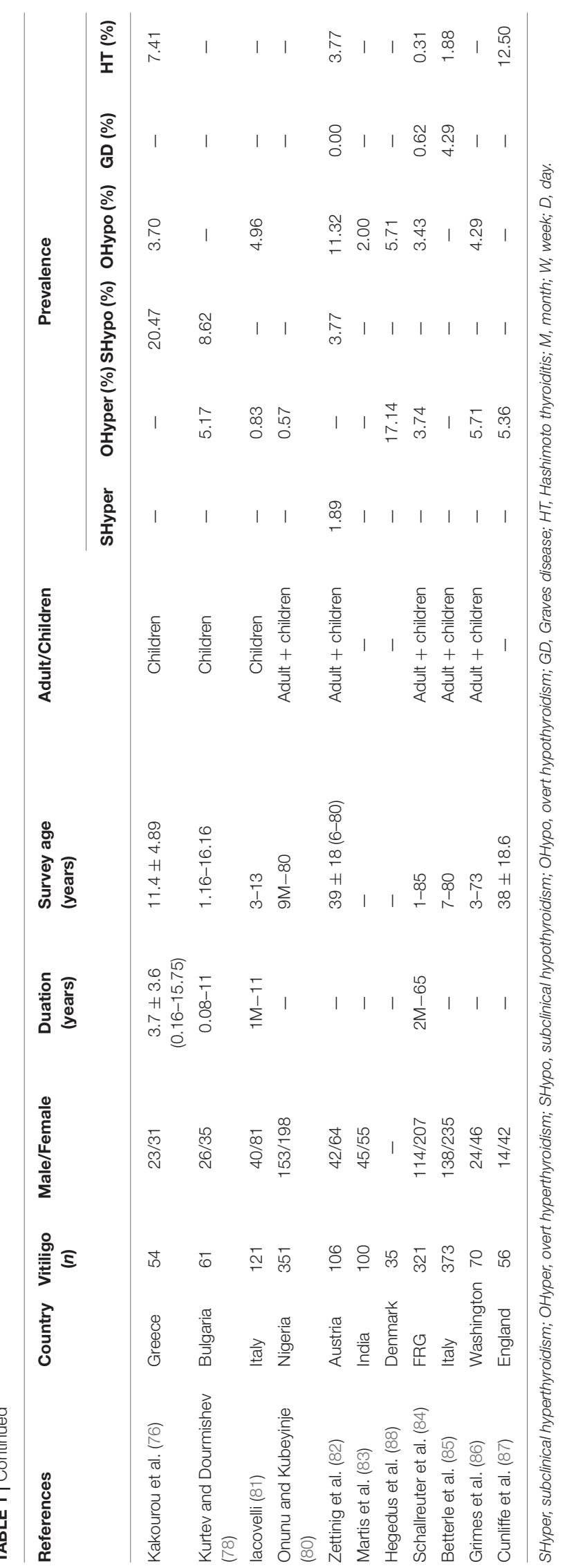

characteristics were extracted: first authors' name, year of publication, country area, number of vitiligo patients, number of different type, or stage of vitiligo patients who have thyroid disorders, number of male and female patients, number, or prevalence of thyroid disorders in vitiligo patients, duration of vitiligo, survey age, adults or children.

\section{Data Analysis}

All statistical analyses were carried out in Stata software (v15.0; Stata Corp, College Station, TX, USA) and a $p<0.05$ was deemed statistically significant. To explore the prevalence of each thyroid disorder in vitiligo patients, the pooled prevalence and its 95\% CI were calculated. Random-effects models were used, if the $p<0.05, I^{2}>50 \%$, otherwise, a fixed-effect model was selected $\left(p>0.05, I^{2}<50 \%\right)$. Subgroup analyses based on areas, gender, age, vitiligo type, and vitiligo stage were done to assess sources of heterogeneity. Sensitivity analysis was performed by eliminating individual studies one by one. The effect of publication bias was assessed by Egger's test.

\section{RESULTS}

\section{Study Flow and Characteristics}

A total of 3,643 articles were screened. Of these, 3,566 were excluded for the following reasons: not relevant to our topic, duplication, review, not English or Chinese, not providing sufficient information or data mistake, no categorical diagnoses (for example, thyroid goiter). Finally, 77 studies met the inclusion criteria, and were included in this systematic review and metaanalysis (12-88). Of these studies, 2 studies were reported by one author in the same year, sharing the common basic data, but respectively provided some different data. The detailed selection process was shown in Figure 1.

The characteristics of included studies were described in Table 1. The publication years were from 1968 to 2018. The countries covered France, Netherland, Greece, Serbia, Bulgaria, FRG (the Federal Republic of Germany), Italy, Spain, Austria, England, Denmark, USA, Washington, Colorado, California, Canada, Brazil, China, India, Turkey, Korea, Japan, Iran, Thailand, and Nigeria. The areas covered Europe (France, Netherland, Greece, Serbia, Bulgaria, FRG, Italy, Spain, Austria, England, Denmark), North America (USA, Washington, Colorado, California, Canada), South America (Brazil), Asia (China, India, Turkey, Korea, Japan, Iran, Thailand), and Africa (Nigeria). The number of patients with thyroid disorders ranged from 35 to 73,336 .

Six thyroid disorders were described in the study. They were subclinical hyperthyroidism, overt hyperthyroidism, subclinical hypothyroidism, overt hypothyroidism, Graves disease, and Hashimoto thyroiditis. The number of studies on the 6 above mentioned thyroid disorders in vitiligo patients were 54 on overt hypothyroidism, 50 on overt hyperthyroidism, 25 on subclinical hypothyroidism, 19 on Hashimoto thyroiditis, 16 on Graves disease, and 10 on subclinical hyperthyroidism (Table 2). The data of vitiligo patients who accompanied with one of the following 5 thyroid disorders including thyroid cancer, toxic nodular goiter, thyroid adenoma or asymptomatic atrophic 
TABLE 2 | The pooled prevalence and subgroup analysis of thyroid disorders in vitiligo patients.

\begin{tabular}{|c|c|c|c|c|c|c|c|c|c|}
\hline & & $\begin{array}{l}\text { Stratified } \\
\text { factors }\end{array}$ & $\begin{array}{l}\text { No. of } \\
\text { studies }\end{array}$ & $\begin{array}{l}\text { Prevalence } \\
\text { rate }\end{array}$ & $\begin{array}{l}\text { Lower } \\
\text { limit }\end{array}$ & $\begin{array}{l}\text { Upper } \\
\text { limit }\end{array}$ & $\begin{array}{l}\text { Heterogeneity } \\
I^{2}(\%)\end{array}$ & $\begin{array}{l}P \text { from test of } \\
\text { heterogeneity }\end{array}$ & Model \\
\hline \multirow{9}{*}{$\begin{array}{l}\text { Subclinical } \\
\text { hyperthyroidism }\end{array}$} & & Overall & 10 & 0.01 & 0.00 & 0.01 & $0.0 \%$ & 0.568 & Fixed \\
\hline & Area & Europe & 8 & 0.01 & 0.00 & 0.01 & $6.2 \%$ & 0.382 & Fixed \\
\hline & & Asia & 2 & 0.01 & -0.00 & 0.02 & $0.0 \%$ & 0.869 & Fixed \\
\hline & Gender & Male & 2 & 0.01 & -0.00 & 0.02 & $100 \%$ & - & - \\
\hline & Age & Children & 2 & 0.00 & -0.00 & 0.01 & $0.0 \%$ & 0.719 & Fixed \\
\hline & & Adults & 2 & 0.01 & 0.00 & 0.02 & $3.1 \%$ & 0.310 & Fixed \\
\hline & Type & SV & 2 & 0.00 & - & - & - & - & - \\
\hline & & NSV & 6 & 0.01 & 0.00 & 0.01 & $0.0 \%$ & 0.825 & Fixed \\
\hline & Stage & Active & 1 & 0.02 & -0.02 & 0.07 & - & - & - \\
\hline \multirow{10}{*}{ Overt hyperthyroidism } & & $\begin{array}{l}\text { South } \\
\text { America }\end{array}$ & 1 & 0.02 & -0.01 & 0.06 & - & - & - \\
\hline & & Asia & 30 & 0.01 & 0.01 & 0.02 & $87.7 \%$ & 0.000 & Random \\
\hline & & Africa & 1 & 0.01 & -0.00 & 0.01 & - & - & - \\
\hline & Gender & Male & 9 & 0.01 & 0.00 & 0.03 & $81.6 \%$ & 0.000 & Random \\
\hline & & Female & 8 & 0.02 & 0.01 & 0.04 & $81.9 \%$ & 0.000 & Random \\
\hline & Age & Children & 9 & 0.01 & 0.00 & 0.02 & 0.702 & 0.001 & Random \\
\hline & & Adults & 11 & 0.05 & 0.03 & 0.07 & 0.864 & 0.000 & Random \\
\hline & Type & SV & 3 & 0.00 & -0.00 & 0.01 & $42.3 \%$ & 0.188 & Fixed \\
\hline & & NSV & 6 & 0.06 & 0.02 & 0.09 & $95 \%$ & 0.000 & Random \\
\hline & & Generalized & 2 & 0.04 & 0.02 & 0.06 & $34.7 \%$ & 0.216 & Fixed \\
\hline \multirow{10}{*}{$\begin{array}{l}\text { Subclinical } \\
\text { hypothyroidism }\end{array}$} & & $\begin{array}{l}\text { North } \\
\text { America }\end{array}$ & 1 & 0.03 & -0.02 & 0.07 & - & - & - \\
\hline & & $\begin{array}{l}\text { South } \\
\text { America }\end{array}$ & 1 & 0.01 & -0.01 & 0.03 & - & - & - \\
\hline & Gender & Male & 4 & 0.02 & 0.01 & 0.03 & $0.0 \%$ & 0.521 & Fixed \\
\hline & & Female & 3 & 0.03 & 0.01 & 0.04 & $73.6 \%$ & 0.051 & Fixed \\
\hline & Age & Children & 8 & 0.07 & 0.03 & 0.11 & $85.2 \%$ & 0.000 & Random \\
\hline & & Adults & 5 & 0.05 & 0.01 & 0.10 & $80.4 \%$ & 0.000 & Random \\
\hline & Type & SV & 2 & 0.00 & - & - & - & - & - \\
\hline & & NSV & 7 & 0.04 & 0.02 & 0.06 & $77.5 \%$ & 0.000 & Random \\
\hline & Stage & Active & 2 & 0.25 & 0.12 & 0.38 & $0.0 \%$ & - & - \\
\hline & & Stable & 1 & 0.31 & 0.15 & 0.47 & - & - & - \\
\hline \multirow[t]{5}{*}{ Overt hypothyroidism } & & Overall & 54 & 0.03 & 0.03 & 0.04 & $94.1 \%$ & 0.000 & Random \\
\hline & Area & Europe & 13 & 0.06 & 0.04 & 0.09 & $85.5 \%$ & 0.000 & Random \\
\hline & & $\begin{array}{l}\text { North } \\
\text { America }\end{array}$ & 7 & 0.09 & 0.07 & 0.11 & $74.9 \%$ & 0.001 & Random \\
\hline & & $\begin{array}{l}\text { South } \\
\text { America }\end{array}$ & 1 & 0.14 & 0.07 & 0.22 & - & - & - \\
\hline & & Asia & 33 & 0.01 & 0.01 & 0.02 & $89.8 \%$ & 0.000 & Random \\
\hline
\end{tabular}




\begin{tabular}{|c|c|c|c|c|c|c|c|c|c|}
\hline & & $\begin{array}{l}\text { Stratified } \\
\text { factors }\end{array}$ & $\begin{array}{l}\text { No. of } \\
\text { studies }\end{array}$ & $\begin{array}{l}\text { Prevalence } \\
\text { rate }\end{array}$ & $\begin{array}{l}\text { Lower } \\
\text { limit }\end{array}$ & $\begin{array}{l}\text { Upper } \\
\text { limit }\end{array}$ & $\begin{array}{l}\text { Heterogeneity } \\
I^{2}(\%)\end{array}$ & $\begin{array}{l}P \text { from test of } \\
\text { heterogeneity }\end{array}$ & Model \\
\hline & Gender & Male & 10 & 0.02 & 0.01 & 0.03 & $80.9 \%$ & 0.000 & Random \\
\hline & & Female & 9 & 0.06 & 0.04 & 0.08 & $91.7 \%$ & 0.000 & Random \\
\hline & Age & Children & 10 & 0.04 & 0.02 & 0.06 & $86.2 \%$ & 0.000 & Random \\
\hline & & Adults & 7 & 0.02 & 0.01 & 0.04 & $86.6 \%$ & 0.000 & Random \\
\hline & Type & SV & 3 & 0.00 & -0.00 & 0.01 & $0.0 \%$ & 0.734 & Fixed \\
\hline & & NSV & 8 & 0.03 & 0.01 & 0.05 & $86.8 \%$ & 0.000 & Random \\
\hline & & Generalized & 2 & 0.10 & -0.03 & 0.22 & $92.6 \%$ & 0.000 & Random \\
\hline & & Acrofacial & 1 & 0.01 & -0.00 & 0.02 & - & - & - \\
\hline & Stage & Active & 1 & 0.02 & -0.02 & 0.07 & - & - & - \\
\hline \multirow[t]{10}{*}{ Graves disease } & & Overall & 16 & 0.01 & 0.01 & 0.02 & $59.9 \%$ & 0.002 & Random \\
\hline & Area & Europe & 3 & 0.02 & -0.01 & 0.06 & $90.4 \%$ & 0.001 & Random \\
\hline & & $\begin{array}{l}\text { North } \\
\text { America }\end{array}$ & 3 & 0.01 & 0.00 & 0.02 & $76.1 \%$ & 0.015 & Random \\
\hline & & Asia & 10 & 0.01 & 0.01 & 0.02 & $56.4 \%$ & 0.014 & Random \\
\hline & Gender & Male & 4 & 0.01 & 0.01 & 0.01 & $58.1 \%$ & 0.122 & Fixed \\
\hline & & Female & 4 & 0.01 & 0.01 & 0.01 & $0.0 \%$ & 0.502 & Fixed \\
\hline & Type & SV & 2 & 0.00 & - & - & - & - & - \\
\hline & & NSV & 1 & 0.01 & -0.00 & 0.02 & - & - & - \\
\hline & & Generalized & 1 & 0.02 & -0.00 & 0.04 & - & - & - \\
\hline & & Vulgaris & 1 & 0.01 & -0.01 & 0.03 & - & - & - \\
\hline \multirow[t]{13}{*}{ Hashimoto thyroiditis } & & Overall & 19 & 0.02 & 0.01 & 0.03 & $92.2 \%$ & 0.000 & Random \\
\hline & Area & Europe & 6 & 0.04 & 0.01 & 0.07 & $83 \%$ & 0.000 & Random \\
\hline & & $\begin{array}{l}\text { North } \\
\text { America }\end{array}$ & 2 & 0.08 & -0.06 & 0.22 & $87.5 \%$ & 0.005 & Random \\
\hline & & Asia & 11 & 0.02 & 0.01 & 0.03 & $94.7 \%$ & 0.000 & Random \\
\hline & Gender & Male & 6 & 0.00 & 0.00 & 0.00 & $56.8 \%$ & 0.055 & Fixed \\
\hline & & Female & 6 & 0.09 & 0.04 & 0.14 & $85.3 \%$ & 0.000 & Random \\
\hline & Age & Children & 3 & 0.07 & -0.01 & 0.15 & $83.9 \%$ & 0.002 & Random \\
\hline & & Adults & 1 & 0.01 & -0.00 & 0.03 & - & - & - \\
\hline & Type & SV & 4 & 0.00 & - & - & - & - & - \\
\hline & & NSV & 2 & 0.08 & -0.04 & 0.20 & $93.6 \%$ & 0.000 & Random \\
\hline & & Generalized & 3 & 0.09 & 0.06 & 0.13 & $20.7 \%$ & 0.283 & Fixed \\
\hline & & Vulgaris & 1 & 0.03 & 0.00 & 0.06 & - & - & - \\
\hline & & Acrofacial & 1 & 0.10 & -0.01 & 0.21 & - & - & - \\
\hline
\end{tabular}

thyroiditis, was not extracted as only 1 study was reported in each disorder.

The diagnoses of subclinical hyperthyroidism were based on the presence of a low TSH level with both normal FT3 value and normal FT4 value and the diagnosis of overt hyperthyroidism was based on the presence of a low TSH level with both raised FT3 value and raised FT4 value $(52,82)$. The diagnosis of overt hypothyroidism required low FT3 and FT4 values no matter what the TSH level was. Subclinical hypothyroidism was diagnosed on the basis of a raised TSH level with normal T3 and T4 values. Hashimoto's thyroiditis was diagnosed based on the demonstration of circulating thyroid antibodies and diffuse thyroid enlargement or reduced echogenicity on thyroid ultrasonography. And the diagnosis of Graves' disease relies on persistent hyperthyroidism together with positive thyroid antibody and/or increase vascularization on thyroid sonogram, thyroid-stimulating antibodies and diffuse hypercaptation at scintigraphy. Thyroid ophthalmopathy and/or dermopathy are characteristic features of Graves' disease (13).

\section{Pooled Result of the Prevalence of Thyroid Disorders in Patients With Vitiligo}

The pooled prevalence of thyroid disorders in patients with vitiligo were showed in Table 2 . The highest prevalence of thyroid disorder accompanying vitiligo was 0.06 (95\% CI: 0.04-0.07) for subclinical hypothyroidism (Figure 2A). The lowest prevalence was 0.01 (95\% CI: 0.00-0.01) for subclinical hyperthyroidism and 0.01 (95\% CI: 0.01-0.02) for Graves disease.

\section{Subgroup Analysis of the Prevalence of Each Thyroid Disorder in Patients With Vitiligo}

Potentially distorting factors, including area, vitiligo type, the stage of vitiligo, gender, and age were investigated for subgroup 
A

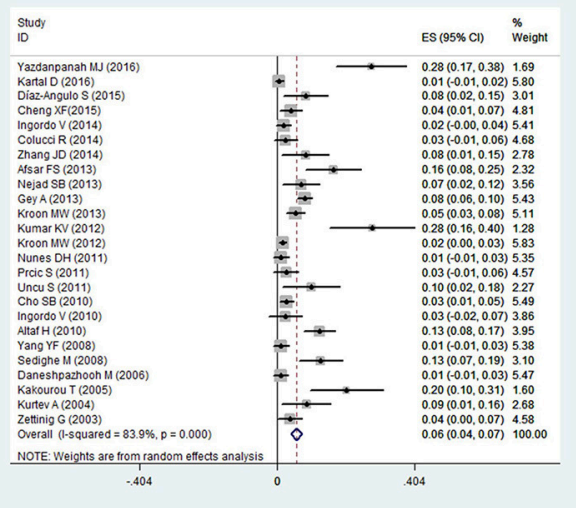

B

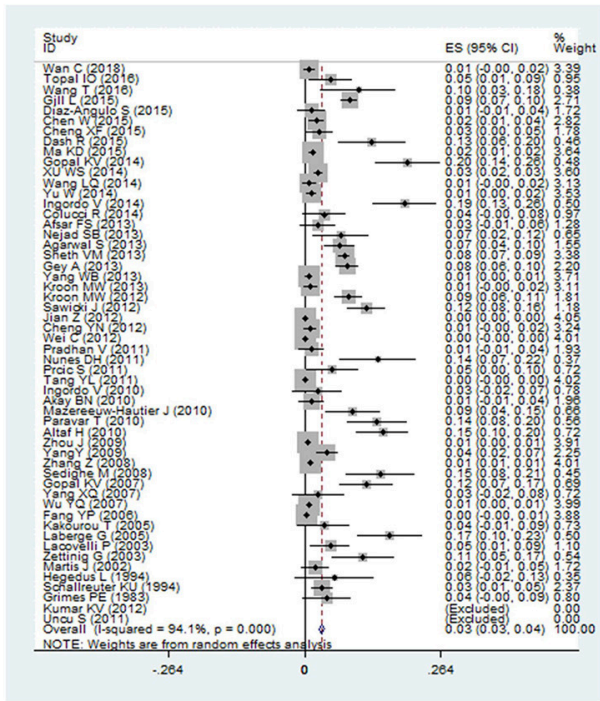

C

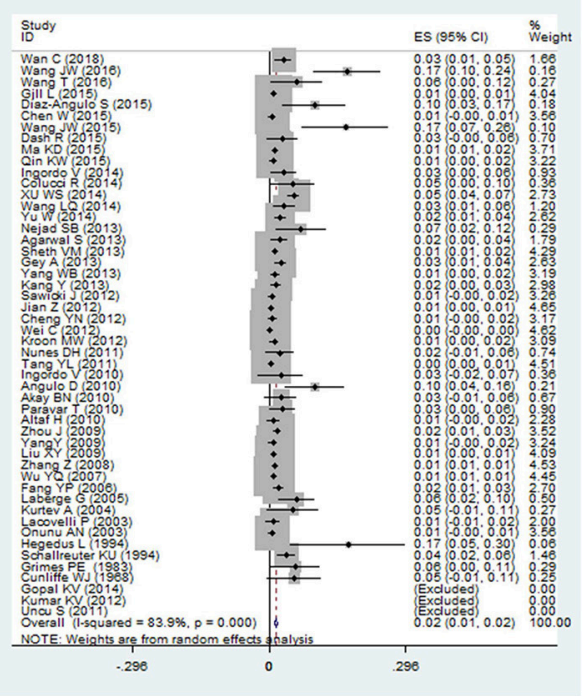

FIGURE 2 | The forest plot of three thyroid disorders in vitiligo patients. The highest prevalence was reported in (A) subclinical hypothyroidism, and a majority of investigators paid attention to (B) overt hypothyroidism, and (C) overt hyperthyroidism in vitiligo patients. analysis. The areas covered Europe, North America, South America, Asia, Africa. For vitiligo type, segmental vitiligo (SV), non-segmental vitiligo (NSV), generalized vitiligo, acrofacial vitiligo, vulgaris vitiligo were classified. When stratified by the stage, it was divided into active vitiligo and stable vitiligo. For the gender, it was divided into male and female. When stratified by age, the groups were children ( $<18$ years) and adults ( $\geq 18$ years). The results of subgroup analysis were listed in Table 2.

Overt hypothyroidism in vitiligo patients was reported in 54 studies. The pooled prevalence was 0.03 (95\% CI: 0.03-0.04) (Figure 2B). The prevalence in Europe, North America, South America and Asia were found to be 0.06 (95\% CI: 0.04-0.09), 0.09 (95\% CI: $0.07-0.11$ ), 0.14 (95\% CI: $0.07-0.22$ ), and 0.01 (95\% CI: 0.01-0.02), respectively. The highest prevalence was 0.14 (95\% CI: $0.07-0.22)$ in South America. Male and female subgroups were 0.02 (95\% CI: 0.01-0.03) and 0.06 (95\% CI: 0.040.08 ), respectively. The prevalence of overt hypothyroidism in the male population was lower than in females. When stratified by age, the prevalence was higher in children 0.04 ( $95 \%$ CI: $0.02-$ $0.06)$ than adults 0.02 (95\% CI: 0.01-0.04). Pooled prevalence of segmental vitiligo, non-segmental vitiligo, generalized vitiligo, and acrofacial vitiligo were 0.00 ( $95 \% \mathrm{CI}:-0.00$ to 0.01 ), 0.03 (95\% CI: 0.01 to 0.05 ), 0.10 (95\% CI: -0.03 to 0.22 ), and 0.01 (95\% CI: -0.00 to 0.02 ), respectively. The prevalence in generalized vitiligo was the highest.

Overt hyperthyroidism in vitiligo patients was reported in 50 studies. The pooled prevalence was 0.02 (95\% CI: 0.01-0.02) (Figure 2C). The prevalence in Europe, North America, South America, Asia and Africa were found to be 0.03 (95\% CI: 0.02 to 0.05 ), 0.01 (95\% CI: 0.01 to 0.01 ), 0.02 (95\% CI: -0.01 to $0.06)$ and 0.01 (95\% CI: 0.01 to 0.02 ), 0.01 (95\% CI: -0.00 to 0.01 ), respectively. The pooled prevalence in Europe was the highest. Male and female subgroups were 0.01 (95\% CI: $0.00-$ 0.03 ) and 0.02 (95\% CI: 0.01-0.04), respectively. When stratified by age, the prevalence was higher in adults 0.05 (95\% CI: $0.03-$ 0.07 ) than children 0.01 (95\% CI: 0.00-0.02). Pooled prevalence of segmental vitiligo, non-segmental vitiligo, generalized vitiligo, and acrofacial vitiligo were 0.00 (95\% CI: -0.00 to 0.01 ), 0.06 ( $95 \%$ CI: 0.02 to 0.09 ), and 0.04 (95\% CI: 0.02 to 0.06 ), respectively. The prevalence of non-segmental vitiligo was higher than the other vitiligo types.

The subgroup analysis of other 4 thyroid disorders including subclinical hyperthyroidism, subclinical hypothyroidism, Graves disease, Hashimoto thyroiditis in vitiligo patients is reported in Table 2.

\section{Sensitivity Analysis}

To examine the stability of the pooled prevalence of thyroid disorders in vitiligo, each study was sequentially excluded for sensitivity analysis. The results demonstrated that some individual studies significantly affected the pooled results in overt hypothyroidism and Hashimoto thyroiditis. The studies of Jian et al. (41) influenced the original results of overt hypothyroidism in vitiligo patients. After removing the study, the pooled prevalence increased by $0.54 \%$ (from 3.23 to $3.77 \%$ ). 

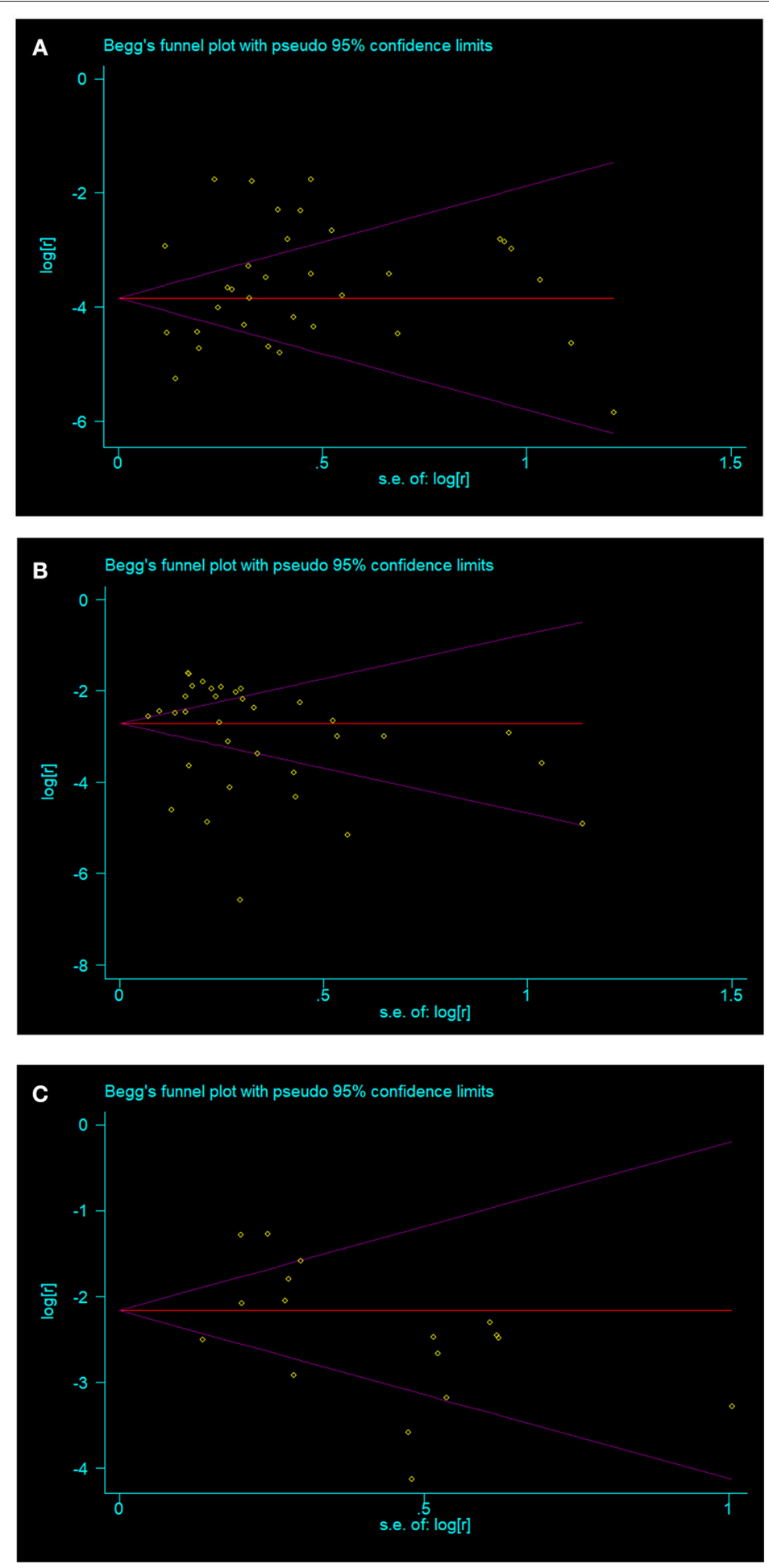

FIGURE 3 | The three thyroid disorders in vitiligo patients with no publication bias (A) overt hyperthyroidism; (B) overt hypothyroidism; (C) subclinical hypothyroidism.

After removing the study of Bae et al. (15) and Tang et al. (55) of Hashimoto thyroiditis in vitiligo patients, the pooled prevalence increased by $3.47 \%$ (from 1.94 to $5.41 \%$ ).

\section{Publication Bias}

No publication bias were found in papers on overt hyperthyroidism ( $t=1.16, p=0.256$ ) (Figure 3A), overt 
hypothyroidism ( $t=0.95, p=0.350)$ (Figure 3B), and subclinical hypothyroidism $(t=-1.36, p=0.194)$ (Figure 3C). Publication bias was found in the prevalence of Graves disease $(t=3.32, p=0.021)$ and Hashimoto thyroiditis $(t=2.96$, $p=0.012$ ) in patients with vitiligo. Publication bias was not done in subclinical hyperthyroidism in vitiligo patients as there were insufficient observations.

\section{DISCUSSION}

Genome-wide association studies suggesting the relationship between vitiligo and thyroid disorders may be explained by the sharing of a subset of susceptibility gene (89-97). For example, genome-wide linkage analysis in families identified an autoimmunity susceptibility locus on chromosome 1 in patients with both vitiligo and Hashimoto's thyroiditis (96-98). In 2012, Vrijmanc et reported a systematic review about the prevalence of abnormal thyroid function test or elevated thyroid antibodies in vitiligo patients, covering 48 studies (99). The study reminds clinicians should be aware of the possibility of thyroid function changes in patients with vitiligo, however, it did not elaborate specific thyroid dysfunction in vitiligo patients. From a different point, the present systematic review summarized the results of the studies which have categorical diagnoses. The present review involving 77 studies with 3,643 vitiligo subjects supports a significant association between vitiligo and at least one thyroid disorders. The thyroid disorders were subclinical hyperthyroidism, overt hyperthyroidism, Graves disease, subclinical hypothyroidism, overt hypothyroidism, Hashimoto thyroiditis. Twenty-five studies reported the prevalence of subclinical hypothyroidism in vitiligo and the prevalence was the highest (6\%) among the six thyroid disorders. Subclinical hyperthyroidism or Graves disease had the lowest prevalence (1\%) in vitiligo patients, correspondingly, only approximately 10 studies were, respectively reported about these diseases.

A majority of investigators paid attention to overt hypothyroidism (54 studies) and overt hyperthyroidism (50 studies) in vitiligo patients, although the prevalence of these two disorders (3 and 2\%) were lower than that of subclinical hypothyroidism. Overt hypothyroidism patients may experience weight gain, hair loss, dry skin, cold intolerance, constipation, muscle aches, or impaired memory (100-102). Overt hyperthyroidism patients may present with irritability, nervousness and heat intolerance $(101,103)$.

Our study investigated the potentially distorting factors, including area, gender, age, vitiligo type and stage of vitiligo. The prevalence of overt hyperthyroidism, overt hypothyroidism, Graves disease, and Hashimoto thyroiditis in Europe were higher than in Asia, in contrast, the prevalence of subclinical hypothyroidism in Europe were lower than in Asia. Genetic factor and iodine intaking habit may explain the disparity. The risk of thyroid dysfunction in female vitiligo patients is

\section{REFERENCES}

1. Iannella G, Greco A, Didona D, Didona B, Granata G, Manno A, et al. Vitiligo: pathogenesis, clinical variants and treatment approaches. Autoimmun Rev. (2016) 15:335-43. doi: 10.1016/j.autrev.2015.12.006 equal or greater than male, suggesting a gender-relationship between thyroid disorders and vitiligo. Men and women have sexual dimorphism of the immune response $(104,105)$. The British vitiligo guideline suggests that adult vitiligo patients should regularly screen for thyroid disorders. The present systematic review supports this recommendation in adult vitiligo patients with subclinical hyperthyroidism and overt hyperthyroidism. However, as for subclinical hypothyroidism, overt hypothyroidism and Hashimoto thyroiditis, children had higher prevalence than adult.

In the present review, all thyroid disorders were found in NSV, but not in SV. SV is characterized by early involvement of follicular melanocyte reservoir, early age of onset, and rapid stabilization (106), whereas NSV typically evolves over time and associates with thyroid disease frequently (107). Ethnic background may explain the disparity $(91,107)$. Different clinical subtypes of NSV have been described, including generalized, acrofacial, and vulgaris types. However, very few studies were included, so we can't draw a clear conclusion. As for the subgroup analysis between active vitiligo and stable vitiligo, 2 thyroid dysfunctions (overt hyperthyroidism and subclinical hypothyroidism) were studied but no definite results were found.

Several limitations of this meta-analysis must be considered. As there were insufficient studies, publication biases were not done about subclinical hyperthyroidism, and publication bias was found in Graves disease and Hashimoto thyroiditis. Studies about vitiligo type and stage were scant. This may have influenced confidence intervals and limited the generalizability of findings. Besides, 3 studies were not included due to the language restrictions.

In conclusion, the systematic review and meta-analysis showed that 6 thyroid disorders showed various prevalence in vitiligo. The highest prevalence was in subclinical hypothyroidism, and the lowest was in subclinical hyperthyroidism or Graves disease. The results of the current review provide useful estimates of the burden of thyroid disorders in vitiligo patients. Screening vitiligo patients for thyroid disorders seem reasonable, in an effort to detect potential thyroid diseases or to assess the risk of future onset.

\section{AUTHOR CONTRIBUTIONS}

JY and CS conceived, designed and performed the article. SJ, YL, and $\mathrm{YZ}$ acquisition of data. H-DC, X-HG, and YW participated in revising the manuscript. All authors contributed to manuscript revision, read and approved the submitted version.

\section{FUNDING}

The study was supported by Liaoning Provincial Natural Science Fund (Code 201602837).

2. Xie H, Zhou F, Liu L, Zhu G, Li Q, Li C, et al. Vitiligo: how do oxidative stressinduced autoantigens trigger autoimmunity? J Dermatol Sci. (2016) 81:3-9. doi: 10.1016/j.jdermsci.2015.09.003

3. Howitz J, Brodthagen H, Schwartz M, Thomsen K. Prevalence of vitiligo: epidemiological survey on the Isle of Bornholm, Denmark. 
Arch Dermatol. (1977) 113:47-52. doi: 10.1001/archderm.1977.016400100 49006

4. Sehgal VN, Srivastava G. Vitiligo: compendium of clinical-epidemiological features. Indian J Dermatol Venereol Leprol. (2007) 73:149-56. doi: $10.4103 / 0378-6323.32708$

5. Herane MI. Vitiligo and leukoderma in children. Clin Dermatol. (2003) 21:283-95. doi: 10.1016/S0738-081X(03)00048-8

6. Alkhateeb A, Fain PR, Thody A, Bennett DC, Spritz RA. Epidemiology of vitiligo and associated autoimmune diseases in Caucasian probands and their relatives. Pigment Cell Res. (2003) 16:208-14. doi: 10.1034/j.1600-0749.2003.00032.x

7. McLeod DS, Cooper DS. The incidence and prevalence of thyroid autoimmunity. Endocrine (2012) 42:252-65. doi: $10.1007 /$ s12020-012-9703-2

8. Fallahi P, Ferrari SM, Ruffilli I, Elia G, Biricotti M, Vita R, et al. The association of other autoimmune diseases in patients with autoimmune thyroiditis: review of the literature and report of a large series of patients. Autoimmun Rev. (2016) 15:1125-8. doi: 10.1016/j.autrev.2016.09.009

9. Schunter JA, Löffler D, Wiesner T, Kovacs P, Badenhoop K, Aust G. A novel FoxD3 variant is associated with vitiligo and elevated thyroid auto-antibodies. J Clin Endocrinol Metab. (2015) 100:1335-42. doi: $10.1210 / j c .2015-2126$

10. Gawkrodger DJ, Ormerod AD, Shaw L, Mauri-Sole I, Whitton ME, Watts MJ, et al. Guideline for the diagnosis and management of vitiligo. $\mathrm{Br} J$ Dermatol. (2008) 159:1051-76. doi: 10.1111/j.1365-2133.2008.08881.x

11. Menke HE, van Everdingen JJ. Richtlijn Vitiligo. Nd Tijdschr Geneeskd. (2006) 150:1976-81.

12. Wan C, Chen L. Clinical Analysis of Childhood Vitiligo and Adulthood Vitiligo in Jiangxi Province. Master dissertation, Nanchang University, Nanchang (2018).

13. Vachiramon V, Harnchoowong S, Onprasert W, Chanprapaph K. Prevalence of thyroid abnormalities in thai patients with vitiligo. Biomed Res Int. (2017). 2017:1-6. doi: 10.1155/2017/7502935

14. Wang JW, Wang JX. Determination and Analysis of Autoantibodies and Thyroid Function in Vitiligo Patients. Master dissertation, Ningxia Medical University, Yinchuan (2016).

15. Bae JM, Lee JH, Yun JS, Han B, Han TY. Vitiligo and overt thyroid diseases: a nationwide population-based study in Korea. J Am Acad Dermatol. (2017) 76:871-8. doi: 10.1016/j.jaad.2016.12.034

16. Wang T, Ding F, Gao XJ. Analysis of serum thyroid function and thyroid autoantibodies results in 67 patients with vitiligo. J Ningxia Med Univ. (2016) 38:1044-6. doi: 10.16050/i.cnki.issnl674-6309.2016.09.017

17. Kartal D, Borlu M, Çinar SL, Kesikoglu A, Utaş S. Thyroid abnormalities in paediatric patients with vitiligo: retrospective study. Adv Dermatol Allergol. (2016) 3:232-34. doi: 10.5114/ada.2016.60617

18. Topal IO, Duman H, Gungor S, Kocaturk E, Kuteyla Can P. Evaluation of the clinical and sociodemographic features of turkish patients with vitiligo. Acta Dermatovenerol Croat. (2016) 24:124-9.

19. Yazdanpanah MJ, Seyedi Noghabi SA, Taghavi M, Afzal Aghaee M, Zabolinejad N. Comparison of autoimmune thyroid disease in patients with progressive and stable vitiligo. J Cutan Med Surg. (2016) 20:135-8. doi: $10.1177 / 1203475415604551$

20. Chen W, Wu YF. Follow-up investigation of vitiligo patients in Yunnan Province. J Dermatol Venereol. (2015) 37:278-80. doi: 10.3969/j.issn.1002-1310.2015.05.015

21. Wang JW, Zhao Y, Wang JX, Zhang L, Liang L, Chen Y. Determination and analysis of thyroid function and thyroid autoantibodies in vitiligo patients. Ningxia Med J. (2015) 37:681-3. doi: 10.13621/j.1001-5949.2015.08.0681

22. Ma KD, Li MH. The analysis of common autoimmune diseases in patients with vitiligo. China Med Front Magaz. (2015) 7:120-2.

23. Cheng XF, Jiang YG, Yin ZY, Yang Y, Zeng XS, Wang FL. Pediatric patients with vitiligo in eastern china: abnormalities in 145 cases based on thyroid function tests and immunological findings. Med Sci Monit. (2015) 21:3216-21. doi: 10.12659/MSM.894981

24. Gill L, Zarbo A, Isedeh P, Jacobsen G, Lim HW, Hamzavi I. Comorbid autoimmune diseases in patients with vitiligo: a cross-sectional study. J Am Acad Dermatol. (2016) 74:295-202. doi: 10.1016/j.jaad.2015. 08.063
25. Dash R, Mohapatra A, Manjunathswamy BS. Anti-thyroid peroxidase antibody in vitiligo: a prevalence study. J Thyroid Res. (2015) 2015:192736. doi: $10.1155 / 2015 / 192736$

26. Qin KW. Comparison of the clinical characteristics of 413 children and adults with vitiligo. Anhui Med Pharmac J. (2015) 19:146-7. doi: 10.3969/j.issn.1009-6469.2015.01.048

27. Yu W, Miao Q. Clinical and Epidemiological Analysis of 606 Patients with Vitiligo in Henan Province. Master dissertation, Zhengzhou University, Zhengzhou (2014).

28. Gopal KV, Rao GR, Kumar YH. Increased prevalence of thyroid dysfunction and diabetes mellitus in Indian vitiligo patients: a case-control study. Indian Dermatol Online J. (2014) 5:456-60. doi: 10.4103/2229-5178.142493

29. Zhang JD, Li J, Xu YX, Chen H, Bai XY, Liu J, et al. Clinical analysis of vitiligo patients combined with autoimmune thyroid diseases. Jiangsu Med J. (2014) 140:294-6. doi: 10.19460/j.cnki.0253-3685.2014.03.016

30. Wang LQ, Li Z, Song WF. Clinical analysis of 215 patients with vitiligo. Chin J Lepr Skin Dis. (2014) 30:80-2.

31. Colucci R, Lotti F, Dragoni F, Arunachalam M, Lotti T, Benvenga S. High prevalence of circulating autoantibodies against thyroid hormones in vitiligo and correlation with clinical and historical parameters of patients. $\mathrm{Br} J$ Dermatol. (2014) 171:786-98. doi: 10.1111/bjd.13286

32. Xu WS, Yu JB. The Research of Clinical Type and Concomitant Disease in 1386 Patients with Vitiligo. Master dissertation, Zhengzhou University, Zhengzhou (2014).

33. Ingordo V, Cazzaniga S, Raone B, Digiuseppe MD, Musumeci ML, Fai D. Circulating autoantibodies and autoimmune comorbidities in vitiligo patients: a multicenter Italian study. Dermatology (2014) 228:240-9. doi: $10.1159 / 000357807$

34. Sheth VM, Guo Y, Qureshi AA. Comorbidities associated with vitiligo: a ten-year retrospective study. Dermatology (2013) 227:311-5. doi: $10.1159 / 000354607$

35. Kang Y, Zhang JL, Shi XH, Ma XL. Analysis and comparison of vitiligo between children and adults. J Clin Dermatol. (2013) 42:454-7.

36. Afsar FS, Isleten F. Prevalence of thyroid function test abnormalities and thyroid autoantibodies in children with vitiligo. Indian J Endocrinol Metab. (2013) 17:1096-9. doi: 10.4103/2230-8210.122636

37. Nejad SB, Qadim HH, Nazeman L, Fadaii R, Goldust M. Frequency of autoimmune diseases in those suffering from vitiligo in comparision with normal population. Pakistan J BiolSci. (2013) 16, 570-4.

38. Agarwal S, Gupta S, Ojha A, Sinha R. Childhood vitiligo: clinicoepidemiologic profile of 268 children from the kumaun region of Uttarakhand, India. Pediatr Dermatol. (2013) 30:348-53. doi: $10.1111 /$ pde. 12032

39. Gey A, Diallo A, Seneschal J, Léauté-Labrèze C, Boralevi F, Jouary T. Autoimmune thyroid disease in vitiligo: multivariate analysis indicates intricate pathomechanisms. $\mathrm{Br} J$ Dermatol. (2013) 168, 756-761. doi: $10.1111 /$ bjd.12166

40. Wei C, Ma CL, Gao TW, Li CY. Clinical features and therapy of 73 cases of congenital vitiligo. Chin J Aesthetic Med. (2012) 21:1580-2. doi: 10.15909/j.cnki.cn61-1347/r.2012.11.076

41. Jian Z, Li K, Liu BM, Li Q, Song L, Song P, et al. Clinical characteristics and therapeutic efficacy analysis on 10000 cases of vitiligo. Chin J Aesthetic Med. (2012) 21:1577-80. doi: 10.15909/j.cnki.cn61-1347/r.2012.11.094

42. Cheng YN, Miao Q, Zhang JA, Jia MY. Clinical analysis of 287 cases of vitiligo. Chin J Derm Venereol. (2012) 26:806-7.

43. Sawicki J, Siddha S, Rosen C. Vitiligo and associated autoimmune disease: retrospective review of 300 patients. J Cutan Med Surg. (2012) 16:261-6. doi: $10.1177 / 120347541201600408$

44. Kroon MW, Vrijman C, Chandeck C, Wind BS, Wolkerstorfer A, Luiten RM, et al. High prevalence of autoimmune thyroiditis in children and adolescents with vitiligo. Horm Res Paediatr. (2013) 79:137-44. doi: 10.1159/000 348388

45. Yang WB, Wang JX. Clinical Retrospective Study of 540 Cases of Vitiligo in Ningxia and the Surrounding Area. Master dissertation, Ningxia Medical University, Yinchuan (2013).

46. Kumar KV, Priya S, Sharma R, Kapoor U, Saini M, Bisht YS. Autoimmune thyroid disease in patients with vitiligo: prevalence study in India. Endocr Pract. (2012) 18:194-9. doi: 10.4158/EP11205.OR 
47. Kroon MW, Joore IC, Wind BS, Leloup MA, Wolkerstorfer A, Luiten RM. Low yield of routine screening for thyroid dysfunction in asymptomatic patients with vitiligo. Br J Dermatol. (2012) 166:532-38. doi: 10.1111/j.1365-2133.2011.10717.x

48. Pradhan V, Patwardhan M, Thakkar V, Kharkar V, Khopkar U, Ghosh $\mathrm{K}$, et al. Vitiligo patients from India (Mumbai) show differences in clinical, demographic and autoantibody profiles compared to patients in western countries. J Eur Acad Dermatol Venereol. (2013) 27:279-86. doi: 10.1111/j.1468-3083.2011.04367.x

49. Cho SB, Kim JH, Cho S, Park JM, Park YK, Oh SH. Vitiligo in children and adolescents: association with thyroid dysfunction. J Eur Acad Dermatol Venereol. (2011) 25:64-7. doi: 10.1111/j.1468-3083.2010.03694.x

50. Nunes DH, Esser LM. Vitiligo epidemiological profile and the association with thyroid disease. An Bras Dermatol. (2011) 86:241-8. doi: 10.1590/S0365-05962011000200006

51. Prćić S, Djuran V, Katanić D, Vlaški J, Gajinov Z. Vitiligo and thyroid dysfunction in children and adolescents. Acta Dermatovenerol Croat. (2011) 19:248-54.

52. Ingordo V, Gentile C, Iannazzone SS, Cusano F, Naldi L. Vitiligo and autoimmunity: an epidemiological study in a representative sample of young Italian males. J Eur Acad Dermatol Venereol. (2011) 25:105-9. doi: 10.1111/j.1468-3083.2010.03696.x

53. Uncu S, Yayli S, Bahadir S, Okten A, Alpay K. Relevance of autoimmune thyroiditis in children and adolescents with vitiligo. Int J Dermatol. (2011) 50:175-9. doi: 10.1111/j.1365-4632.2010.04665.x

54. Narita T, Oiso N, Fukai K, Kabashima K, Kawada A, Suzuki T. Generalized vitiligo and associated autoimmune diseases in Japanese patients and their families. Allergol Int. (2011) 60:505-8. doi: 10.2332/allergolint.11-OA0303

55. Tang YL, Xu AE, Wang T, Zheng JL. Retrospective analysis on 1367 cases of localized vitiligo. Chin J Dermato Venerol Integ Trad W Med. (2011) 10:350-2.

56. Poojary SA. Vitiligo and associated autoimmune disorders: a retrospective hospital-based study in Mumbai, India. Allergol Immunopathol. (2011) 39:356-61. doi: 10.1016/j.aller.2010.12.007

57. Díaz Angulo S, Marcos L, Sánchez Castañón M, Muñoz Cacho P, Rodríguez Fernández F, Armesto Alonso S, et al. Thyroid autoimmunity and vitiligo. Eur J Allergy Clin Immunol. (2010) 65:461-62.

58. Altaf H, Shah IH, Ahmad QM. Evaluation of thyroid function and presence of anti-thyroid peroxidase antibodies in patients with vitiligo. Egyptian Dermatol Online J. (2010) 6:1-13.

59. Akay BN, Bozkir M, Anadolu Y, Gullu S. Epidemiology of vitiligo, associated autoimmune diseases and audiological abnormalities: Ankara study of 80 patients in Turkey. J Eur Acad Dermatol Venereol. (2010) 24:1144-50. doi: 10.1111/j.1468-3083.2010.03605.x

60. Liu XY, Xu AE, Jin YH, Zhang L, Sun XC, Huang B, et al. Clinical analysis of 339 cases of late onset vitiligo in Zhejiang provience. Chin J Dermatol. (2009) 42:695-8.

61. Zhou J, Fu WW. Clinical and Immunological Features of Adult Vitiligo. Master dissertation. Fudan University, Shanghai (2009).

62. Yang Y, Lin X, Fu W, Luo X, Kang K. An approach to the correlation between vitiligo and autoimmune thyroiditis in Chinese children. Clin Exp Dermatol. (2010) 35:706-10. doi: 10.1111/j.1365-2230.2009.03671.x

63. Yang Y, Luo XQ, Fu WW. Abnormality of parameters of thyroid function and incidence of autoimmune diseases in children with vitiligo. Chin J Dermatol. (2009) 42:377-9.

64. Tanioka M, Yamamoto Y, Katoh M, Takahashi K, Miyachi Y. Vitiligo vulgaris and autoimmune diseases in Japan: a report from vitiligo clinic in Kyoto University Hospital. Dermatoendocrinology(2009) 1:43-5. doi: 10.4161/derm.1.1.7306

65. Mazereeuw-Hautier J, Bezio S, Mahe E, Bodemer C, Eschard C, Viseux V. Segmental and nonsegmental childhood vitiligo has distinct clinical characteristics: a prospective observational study. J Am Acad Dermatol. (2010) 62:945-9. doi: 10.1016/j.jaad.2009. 06.081

66. Birlea SA, Fain PR, Spritz RA. A Romanian population isolate with high frequency of vitiligo and associated autoimmune diseases. Arch Dermatol. (2008) 144:310-6. doi: 10.1001/archderm.144.3.310
67. Zhang Z, Yang S, Zhang XJ. The Analysis of Genetics and Associated Autoimmune Diseases in Chinese Vitiligo Patients. Master dissertation. Anhui Medical University. Anhui (2008).

68. Yang YF, Qing ZJ. Detection of Serum Thyroid Autoantibodies and Thyroid Hormones in Patients with Vitiligo. Master dissertation, Central South University, Changsha (2008)

69. Sedighe M, Gholamhossein G. Thyroid dysfunction and thyroid antibodies in Iranian patients with vitiligo. Indian J Dermatol. (2008) 53:9-11. doi: 10.4103/0019-5154.39733

70. Yang XQ, Du Y, Deng M, Chen DY. The study on the association between the prevalence of autoimmune thyroid disease and vitiligo. Chin J Dermatol. (2007) 21:26-7.

71. Wu YQ, Zhang XJ, Yang S. Clinical and Epidemiology Study on Segmental Vitiligo in Chinese. Master dissertation. Anhui Medical University. Anhui (2007).

72. Fang YP, Tian QF. Clinical analysis and study on 562 cases of vitiligo patient. He Nan Med Res. (2007) 16, 61-3.

73. Paravar T, Lee DJ. Vitiligo in an urban academic setting. Int J Dermatol. (2010) 49:39-43. doi: 10.1111/j.1365-4632.2009.04175.x

74. Gopal KV, Rama Rao GR, Kumar YH, Appa Rao MV, Srikant VP. Vitiligo: a part of a systemic autoimmune process. Indian J Dermatol Venereol Leprol. (2007) 73:162-5. doi: 10.4103/0378-6323.32710

75. Daneshpazhooh M, Mostofizadeh GM, Behjati J, Akhyani M, Robati RM. Anti-thyroid peroxidase antibody and vitiligo: a controlled study. BMC Dermatol. (2006) 6:3. doi: 10.1186/1471-5945-6-3

76. Kakourou T, Kanaka-Gantenbein C, Papadopoulou A, Kaloumenou E, Chrousos GP. Increased prevalence of chronic autoimmune (Hashimoto's) thyroiditis in children and adolescents with vitiligo. J Am Acad Dermatol. (2005) 53:220-3. doi: 10.1016/j.jaad.2005.03.032

77. Laberge G, Mailloux CM, Gowan K, Holland P, Bennett DC, Fain $\mathrm{PR}$, et al. Early disease onset and increased risk of other autoimmune diseases in familial generalized vitiligo. Pigment Cell Res. (2005) 18:300-5. doi: 10.1111/j.1600-0749.2005.00242.x

78. Kurtev A, Dourmishev AL. Thyroid function and autoimmunity in children and adolescents with vitiligo. J Eur Acad Dermatol Venereol. (2004) 18:109-11. doi: 10.1111/j.1468-3083.2004.00728.x

79. Díaz-Angulo S, López-Hoyos M, Muñoz-Cacho P, López-Escobar M, González-López MA. High prevalence of thyroid autoimmunity in patients with alopecia areata and vitiligo: a controlled study. The Australasian College of Dermatologists. Australas J Dermatol. (2015) 56:142-3. doi: 10.1111/ajd.12321

80. Onunu AN, Kubeyinje EP. Vitiligo in the Nigerian African: a study of 351 patients in Benin City, Nigeria. Int J Dermatol. (2003) 42:800-2. doi: 10.1046/j.1365-4362.2003.01908.x

81. Iacovelli P, Sinagra JL, Vidolin AP, Marenda S, Capitanio B, Leone G, et al. Relevance of thyroiditis and of other autoimmune diseases in children with vitiligo. Dermatology (2005) 210:26-30. doi: 10.1159/000081479

82. Zettinig G, Tanew A, Fischer G, Mayr W, Dudczak R, Weissel M. Autoimmune diseases in vitiligo: do anti-nuclear antibodies decrease thyroid volume? Clin Exp Immunol. (2003) 131:347-54. doi: 10.1046/j.1365-2249.2003.02089.x

83. Martis J, Bhat R, Nandakishore B, Shetty JN. A clinical study of vitiligo. Indian J Dermatol Venereol Leprol. (2002) 68:92-3.

84. Schallreuter KU, Lemke R, Brandt O, Schwartz R, Westhofen M, Montz R. Vitiligo and other diseases: coexistence or true association? Hamburg study on 321 patients. Dermatology (1994) 188:269-75. doi: 10.1159/0002 47164

85. Betterle C, Caretto A, De Zio A, Pedini B, Veller-Fornasa C, Cecchetto $A$, et al. Incidence and significance of organ-specific autoimmune disorders (clinical, latent or only autoantibodies) in patients with vitiligo. Dermatologica (1985) 171:419-23. doi: 10.1159/000249466

86. Grimes PE, Halder RM, Jones C, Chakrabarti SG, Enterline J, Minus HR, et al. Autoantibodies and their clinical significance in a black vitiligo population. Arch Dermatol. (1983) 119:300-3. doi: 10.1001/archderm.1983.01650280028010

87. Cunliffe WJ, Hall R, Newell DJ, Stevenson CJ. Vitiligo, thyroid disease and autoimmunity. Br J Dermatol. (1968) 80:135-9. doi: $10.1111 /$ j.1365-2133.1968.tb12282.x 
88. Hegedus L, Heidenheim M, Gervil M, Hjalgrim H, Høier-Madsen M. High frequency of thyroid dysfunction in patients with vitiligo. Acta Derm Venereol. (1994) 74:120-3.

89. Czajkowski R, Mecinska-Jundziłł K. Current aspects of vitiligo genetics. Postepy Dermatol Alergol. (2014) 31:247-55. doi: 10.5114/pdia.2014. 43497

90. Weetman AP. The genetics of autoimmune thyroid disease. Horm Metab Res. (2009) 41:421-5. doi: 10.1055/s-0029-1214415

91. Spritz RA. Shared genetic relationships underlying generalized vitiligo and autoimmune thyroid disease. Thyroid (2010) 20:745-54. doi: $10.1089 /$ thy.2010.1643

92. Jin Y, Birlea SA, Fain PR, Ferrara TM, Ben S, Riccardi SL, et al. Genomewide association analyses identify 13 new susceptibility loci for generalized vitiligo. Nat Genet. (2012) 44:676-80. doi: 10.1038/ng.2272

93. Simmonds MJ. GWAS in autoimmune thyroid disease: redefining our understanding of pathogenesis. Nat Rev Endocrinol. (2013) 9:277-87. doi: $10.1038 /$ nrendo.2013.56

94. Medici M, Porcu E, Pistis G, Teumer A, Brown SJ, Jensen RA. Identification of novel genetic loci associated with thyroid peroxidase antibodies and clinical thyroid disease. PLoS Genet. (2014) 10:e1004123. doi: 10.1371/journal.pgen.1004123

95. Alkhateeb A, Jarun Y, Tashtoush R. Polymorphisms in NLRP1 gene and susceptibility to autoimmune thyroid disease. Autoimmunity (2013) 46:215-21. doi: 10.3109/08916934.2013.768617

96. Alkhateeb A, Stetler GL, Old W, Talbert J, Uhlhorn C, Taylor M, et al. Mapping of an autoimmunity susceptibility locus (AIS1) to chromosome 1p31.3-p32.2. Hum Mol Genet. (2002) 11:661-7.

97. Fain PR, Gowan K, LaBerge GS, Alkhateeb A, Stetler GL, Talbert J, et al. A genomewide screen for generalized vitiligo: confirmation of AIS1 on chromosome $1 \mathrm{p} 31$ and evidence for additional susceptibility loci. Am J Hum Genet. (2003) 72:1560-4. doi: 10.1086/375451

98. Spritz RA, Gowan K, Bennett DC, Fain PR. Novel vitiligo susceptibility loci on chromosomes 7 (AIS2) and 8 (AIS3), confirmation of SLEV1 on chromosome17, and their roles in an autoimmune diathesis. Am J Hum Genet. (2004) 74:188-91. doi: 10.1086/ 381134

99. Vrijman C, Kroon MW, Limpens J, Leeflang MM, Luiten RM, van der Veen JP, et al. The prevalence of thyroid disease in patients with vitiligo: a systematic review. Br J Dermatol. (2012) 167:1224-35. doi: 10.1111/j.1365-2133.2012.11198.x

100. Watt T, Groenvold M, Rasmussen AK, Bonnema SJ, Hegedüs L, Bjorner JB, et al. Quality of life in patients with benign thyroid disorders. Rev Eur J Endocrinol. (2006) 154:501-10. doi: 10.1530/eje.1.02124

101. Fitzgerald, P. A. (2016). Endocrine Disorders. Current Medical Diagnosis and Treatment. 55th ed. New York, NY: McGraw-Hill, Education (2016). p. 1078-189.

102. Garmendia Madariaga A, Santos Palacios S, Guillén-Grima F, Galofré JC. The incidence and prevalence of thyroid dysfunction in Europe: a meta-analysis. J Clin Endocrinol Metab. (2014) 99:923-31. doi: 10.1210/jc.2013-2409

103. Ross DS, Burch HB, Cooper DS, Greenlee MC, Laurberg P, Maia AL, et al. 2016 American thyroid association guidelines for diagnosis and management of hyperthyroidism and other causes of thyrotoxicosis. Thyroid (2016) 26:1343-421. doi: 10.1089/thy.2016.0229

104. Chiovato L, Lapi P, Fiore E, Tonacchera M, Pinchera A. Thyroid autoimmunity and female gender. J Endocrinol Invest. (1993) 16:384-91. doi: $10.1007 / \mathrm{BF} 03348863$

105. Ansar Ahmed S, Penhale WJ, Talal N. Sex hormones, immune responses, and autoimmune diseases. Mechanisms of sex hormone action. Am J Pathol. (1985) 121:531-51

106. van Geel N, Mollet I, Brochez L, Dutré M, De Schepper S, Verhaeghe E, et al. New insights in segmental vitiligo: case report and review of theories. $\mathrm{Br} \mathrm{J}$ Dermatol. (2012) 166, 240-6. doi: 10.1111/j.1365-2133.2011.10650.x

107. Ezzedine K, Eleftheriadou V, Whitton M, van Geel N. Vitiligo. Lancet (2015) 386:74-84. doi: 10.1016/S0140-6736(14)60763-7

Conflict of Interest Statement: The authors declare that the research was conducted in the absence of any commercial or financial relationships that could be construed as a potential conflict of interest.

Copyright (c) 2019 Yuan, Sun, Jiang, Lu, Zhang, Gao, Wu and Chen. This is an open-access article distributed under the terms of the Creative Commons Attribution License (CC BY). The use, distribution or reproduction in other forums is permitted, provided the original author(s) and the copyright owner(s) are credited and that the original publication in this journal is cited, in accordance with accepted academic practice. No use, distribution or reproduction is permitted which does not comply with these terms. 